Syazana et al., Afr J Tradit Complement Altern Med. (2013) 10(2):180-188

http://dx.doi.org/10.4314/ajtcam.v10i2.2

\title{
ANALYSIS OF VOLATILE COMPOUNDS OF MALAYSIAN TUALANG (KOOMPASSIA EXCELSA) HONEY USING GAS CHROMATOGRAPHY MASS SPECTROMETRY
}

\author{
Nurul Syazana MS ${ }^{1}$, SH Gan ${ }^{2}$, Halim AS ${ }^{1 *}$ Nurul Syazana Mohamad Shah ${ }^{1}$, Siew Hua Gan ${ }^{2}$, Halim \\ Ahmad Sukari ${ }^{1}$
}

${ }^{1}$ Reconstructive Sciences Unit, School of Medical Sciences, Health Campus, Universiti Sains Malaysia, Kubang Kerian 16150, Kelantan, Malaysia ${ }^{2}$ Human Genome Centre, School of Medical Sciences, Universiti Sains Malaysia, 16150 Kubang Kerian, Kelantan, Malaysia.

*E-mail: ashalim@,kb.usm.my

\begin{abstract}
The constituents of honey's volatile compounds depend on the nectar source and differ depending on the place of origin. To date, the volatile constituents of Tualang honey have never been investigated. The objective of this study was to analyze the volatile compounds in local Malaysian Tualang honey. A continuous extraction of Tualang honey using five organic solvents was carried out starting from non-polar to polar solvents and the extracted samples were analysed using gas chromatography-mass spectrometry (GC-MS). Overall, 35 volatile compounds were detected. Hydrocarbons constitute 58.5\% of the composition of Tualang honey. Other classes of chemical compounds detected included acids, aldehydes, alcohols, ketones, terpenes, furans and a miscellaneous group. Methanol yielded the highest number of extracted compounds such as acids and 5-(Hydroxymethyl) furfural (HMF). This is the first study to describe the volatile compounds in Tualang honey. The use of a simple one tube, stepwise, non-thermal liquid-liquid extraction of honey is a advantageous as it prevents sample loss. Further research to test the clinical benefits of these volatile compounds is recommended.
\end{abstract}

Key words: Tualang honey, volatile composition, GC-MS.

List of non-standard abbreviations: $\mathrm{Na}_{2} \mathrm{SO}_{4}$ : anhydrous disodium sulfate powder; GC-MS: gas chromatography-mass spectrometry; FAMA: Federal Agriculture Marketing Authority; Amu: atomic mass unit; TIC: total ion count; SPME: solid phase microextraction; AHA: alpha-hydroxy acid; HMF: 5-(Hydroxymethyl) furfural.

\section{Introduction}

Since ancient times, honey has been valued for its medicinal properties. Honey has been used to treat infections in various types of wounds including burns, diabetic ulcers, pressure ulcers, traumatic ulcers and Fournier's gangrene (Molan, 2001; Schumacher, 2004; Simon et al., 2006). The antiseptic and antibacterial properties of honey have also been investigated (Jeffrey et al., 1996; Tan et al., 2009). There are many types of honey that can be found around the world such as alfalfa honey from Canada, avocado honey from California, manuka honey from New Zealand while Malaysia is famous for gelam, coconut and tualang honeys.

The Tualang tree (Koompassia excelsa) is a majestic tree of the Southeast Asia rainforests best known for the diskshaped honeycombs which hang from its horizontal branches (http://www.blueplanetbiomes.org/tualang.htm). It is mostly found in lowland forests of Penisular Malaysia, southern Thailand, northern Sumatra and Borneo, and can grow to heights greater than 85 meters. The trees are valued by the locals due to its honey. In fact, a standing Tualang tree is more valuable for its honey than if it were felled for its timber. The honey from the combs of this tree is known as Tualang honey, and is produced by Apis dorsata or Asian rock bees.

Generally, honey contains carbohydrates, proteins, lipids and vitamins (Al-Qassemi et al., 2003). Even though the precise composition of honey varies according to the plant species on which the bee forages, the main constituents are thought to be similar in all honeys (Jeffrey et al., 1996). Some compounds have been reported as characteristic components of honey from certain geographic regions. For example, it was suggested that English honeys can be identified by the presence of 1-penten-3-ol as a compound specific to this region (Radovic et al., 2001). It is also possible that the formation of secondary metabolites in plants growing in different regions may differ. Considering only the most recent work in this field, 110 compounds have been detected in 43 authentic honey samples of different botanical and geographic origin (Radovic et al., 2001).

In general, honey volatiles may be derived from the plant or nectar, from the transformation of plant compounds by a honey bee or directly generated by honey bee, from heating or handling during honey processing and storage, or from microbial or environmental contamination (Jerkovic and Marijanovic, 2009). Although the variability of honey flavor mainly depends on its floral origin, the isolation and detection techniques of volatiles may also play a role in determining the results (Allisandrakis et al., 2005).

Continuous liquid-liquid extraction with diethyl ether has been used for the extraction of polar phenolic and acidic substances (Bicchi et al., 1983; Tan et al., 1988; Aljadi et al., 2003). It has also been used for the determination of linalool 

http://dx.doi.org/10.4314/ajtcam.v10i2.2

derivatives in New Zealand honeys (Wilkins wt al., 1993). A simple liquid-liquid extraction method is advantageous as it does not involve heating which may lead to loss of volatiles or the formation of artifacts (Allisandrakis et al., 2005). Therefore, extraction of honey samples using this method is more popular.

The concentration of volatile constituents in honey are very low, therefore a sensitive technique such as gas chromatography-mass spectrometry (GC-MS) is needed. GC-MS is a simple instrument and requires very little time for quantification of compounds when compared to other methods such as high performance liquid chromatography. By using GCMS methods, many important organic compounds have been detected in different types of honeys (Jerkovic and Marijanovic, 2009; ; Baroni et al., 2006; Castro et al., 2006; Luis 2007; Kaškoniene et al., 2008)

Recently we reported the antimicrobial properties of Tualang honey (Tan et al., 2009) but the volatile compounds in Tualang honey from Malaysia remain unknown. To our knowledge, no research has focused on determination of the volatile profile of Tualang honey.

\section{Materials and Methods Sample preparation}

Malaysian Tualang honey samples were obtained from the Federal Agriculture Marketing Authority (FAMA) in Kedah, Malaysia. The honey samples were kept in sealed Teflon-coated plastic vials with silicone septa (Alltech, Milano, Italy) in a cool, dry place and stored for a maximum of one week before extraction.

Due to the high viscosity of pure Tualang honey, the honey was first weighed $(0.5 \mathrm{~g})$ and diluted with $0.5 \mathrm{~mL}$ distilled water (w/v). The mixture was vortexed for 2-3 minutes to ensure adequate mixing between honey and distilled water prior to liquid-liquid extraction. The use of one tube, step-wise, non-thermal liquid-liquid extraction of honey followed by identification of compounds using GC/MS is beneficial as it reduces the possibility of sample loss. All organic solvents were of analytical grade.

\section{Liquid-liquid extraction}

Five different organic solvents with increasing polarity were chosen: 1) petroleum spirit, 2) hexane, 3) dichloromethane, 4) ethyl acetate and 5) methanol. The extraction was run continuously on a single sample.

A continuous liquid-liquid extraction technique using five different organic solvents was selected due to its speed, low cost, and lack of sample heating. Moreover, as reported by Soria et al. (2003), the low polarity solvents used in the initial stage of the continuous liquid-liquid extraction method extract neither water nor sugar from honey. Therefore, this method was employed.

Initially, petroleum spirit $(2 \mathrm{~mL})$ was added to the capped glass tube containing the diluted honey. Then, the mixture was vortexed at $1500 \mathrm{rpm}$ for $3 \mathrm{~min}$ before being centrifuged at $2500 \mathrm{rpm}$ for another $5 \mathrm{~min}$ to separate the organic layer from the aqueous layer. The top layer containing the organic solvent was transferred to new capped glass tubes while the bottom layer was kept for subsequent extraction processing using different organic solvents. Approximately $1.5 \mathrm{~g}$ of anhydrous disodium sulfate powder $\left(\mathrm{Na}_{2} \mathrm{SO}_{4}\right.$, BDH Laboratory supplies, Poole, UK) was added to the top layer to ensure that residual water was removed from the solvent. After that, the sample was further vortexed for 3 minutes and the clear top layer containing the organic extract was transferred into a $1 \mathrm{~mL}$ autosampler vial before GC-MS injection.

For the next extraction, $2 \mathrm{~mL}$ of hexane was added to the bottom layer from the prior extraction. The above steps were then repeated. A similar process was carried out with dichloromethane, followed by ethyl acetate and finally methanol. Organic solvent blanks were included with each GC-MS analysis. Every extraction was injected into the GC-MS system using the parameters described below.

\section{Analysis with GC-MS}

GC-MS analyses were performed on a HP6890 GC coupled with a HP5973 mass spectrometer. The column was a HP5MS fused-silica capillary column ( $30 \mathrm{~m} \times 0.25 \mathrm{~mm}$ i.d.; $0.25 \mu \mathrm{m}$ film thickness), and helium running at a constant pressure of $14.5 \mathrm{psi}$ was used as the carrier gas. One microliter volumes were injected using a splitless mode at an injector temperature of $250^{\circ} \mathrm{C}$. The oven temperature was ramped from 35 to $280^{\circ} \mathrm{C}(1$ minute hold $)$ at a rate of $25^{\circ} \mathrm{C} / \mathrm{min}$. The oven temperature was held at $310^{\circ} \mathrm{C}$ for 6 minutes following each analysis. The total run time for each sample was approximately 90 minutes. The GC-MS interface temperature was set to $280^{\circ} \mathrm{C}$. Mass spectrometry mode was used during analytical scanning from 20-650 atomic mass unit (amu). The ion source temperature was set to $250^{\circ} \mathrm{C}$. The blank was first injected, and was followed by the sample injection. The chromatograms obtained from the total ion count (TIC) were integrated without any correction for co-eluting peaks and the results were expressed as total abundance. All the peaks were identified based on mass spectral matching $(\geq 90 \%)$ from both the NIST and Wiley libraries. Only compounds with $90 \%$ or greater spectral matching accuracy are reported.

\section{Results and Discussion}

Overall, 35 volatile compounds from Tualang honey were successfully identified. This is similar to the studies 

http://dx.doi.org/10.4314/ajtcam.v10i2.2

conducted by Odeh et al. (2007), who identified 30 compounds in Palestinian honey; by Castro Vasquez et al. (2007)., who identified 35 volatile compounds in eucalyptus honey; or by Lušić et al. (2007) who identified 37 compounds from lime tree honey samples using solid phase microextraction (SPME).

Our study detected different classes of chemical compounds including acids, aldehydes, alcohol, ketones, terpenes, hydrocarbons, furans and a miscellaneous group. Previous studies also reported the presence of organic acids (Jerkovic and Marijanovic, 2009.; Kaškoniene et al., 2008; Odeh et al., 2007), aldehydes (Baroni et al., 2006; Odeh et al., 2007; Jerković et al., 2009), alcohols (Odeh et al., 2007), ketones (Castro et al., 2006; Jerković et al., 2009), terpenes (Castro et al., 2006; Kaškoniene et al., 2008), hydrocarbons (Baroni et al., 2006; Kaškoniene et al., 2008; Jerković et al., 2009) and furan derivatives (Baroni et al., 2006; Castro et al., 2006; Kaškoniene et al., 2008) in honey samples.

Classes of compounds detected in other types of honey but not detected in Tualang honey were esters (Jerković et al., 2009), norisoprenoids (carotenoid-derived compounds) Tan et al., 1988; Baroni et al., 2006; Castro et al., 2006) and benzene derivatives such as benzaldehyde, which has been reported as an important constituent of some unifloral honey (Baroni et al., 2006). High content of benzaldehyde has been reported in rosemary (13.4\%), heather (10.3\%) and willow honeys (22.3\%) (De La Fuente et al., 2005; De La Fuente et al., 2007).

The first solvent used, namely petroleum spirit (Table 1) yielded mostly hydrocarbons. Terpenes were only detected following petroleum spirit extraction (Fig 1). In this study, two types of terpenes were identified; cis-linalool oxide and linalool oxide. Linalool has also been identified in Eucalyptus (Castro et al., 2006) and cashew honeys (Luis et al., 2007). It has been reported that the extracts from citrus honey predominantly contain an array of linalool derivatives (more than $80 \%$ of the total extract) (Alissandrakis et al., 2009). However, according to Kaškoniene et al. (2008), the linalool content may increase in honey after three months of storage. Other terpenoid compounds such as 1,8-cineol and p-cymen-8-ol have also been identified in Italian eucalyptus honey analyzed using SPME (Verzera et al., 2001), and are reportedly among the major volatile compounds in most of the Eucalyptus species (Bignell et al., 1994). Camphor is also a terpene found in eucalyptus, rosemary, chestnut and wild flower honeys (Verzera et al., 2001). Terpenes are one of the phytochemicals that contributes to the antimicrobial activity of honey (Saravana et al., 2009).

Dichloromethane was the only organic solvent that did not yield any compounds, perhaps due to the polar nature and the fact that it was heavier than water, therefore its layer was difficult to be separated. Nevertheless, Bouseta et al., (1996) and Vazquez et al. (2006), in their studies have successfully used dichloromethane to extract volatile compounds from eucalyptus honey which has a different composition. The different volatile compounds in honey are related to their floral origin, nectar composition (Kaškoniene et al., 2008) and geographical origin (Yao et al., 2003). This indicates that the volatile composition of Tualang honey is different and that dichloromethane is not a suitable organic solvent for the extraction of volatiles in Tualang honey. The next solvent, ethyl acetate also yielded mainly hydrocarbons. However, we do not discount the possibility of the hydrocarbons coming from the transfer from honeycomb waxes which may affect the volatile compounds detected.

The final organic solvent, methanol extracted more polar volatiles such as acids and alcohols and a wide range of other compounds due to its more polar nature. Overall, it yielded 13 different compounds, which had not been extracted by the organic solvents used at the earlier stages of the extraction. Most of the compounds extracted by methanol were polar molecules such as acids and alcohols. These results indicate that the choice of solvent is very important for extracting different constituents of honey, as different solvents give different results. We conclude that methanol is probably the most suitable solvent to elute active constituents from Tualang honey.

The amount of furfural in our sample, in which both furfural alcohols and 5-hydroxymethyl furfural (HMF) were detected (total relative percentage $8.46 \%$ ), is lower than that detected in samples from Lithuania (0.8\% to $25.5 \%$ ) (De La Fuente et al., 2005) or in lavender honey (11.8\%) but was within recommended. This could be because the SPME method used by both groups of researchers involves some heating as furfural content increases with heat treatment (Baroni et al., 2006; De La Fuente et al., 2005) or with prolonged storage (De La Fuente et al., 2007; Yao et al., 2003). It has been recommended that the HMF content in honey samples should be less than $80 \mathrm{mg} / \mathrm{kg}$ (Zappala et al., 2005) because high levels have been reported to cause DNA damage in human cells and may contribute to obesity and heart disease in humans (Conrad et al., 2010).

The presence of ethanol may be related to the development of yeasts in carbohydrate rich products (De La Fuente et al., 2007). Even though ethanol was not detected in our honey indicating that our honey sample was fresh, a miscellaneous group of compounds including 2, 3-dihydro-3, 5-hydroxy-6-methyl-4H-pyran-4-one has been detected in Tualang honey at low concentration (2.82\%). These compounds have also been detected in lavender honey (6.6\%) (Jerkovic et al., 2001). A similar compound, 3-hydroxy-2-methyl-4H-pyran-4-one has also been found in eucalyptus extracts, where it was attributed to Maillard reactions (Castro-V'Azquez et al., 2003) and was considered to indicate some loss of freshness.

Methyl glycolate (acetic acid) was also detected (6.76\%) in the methanol extracts of Tualang honey. This compound was also found in lavender honey extracts (14.33\%) using SPME (Jerkovic et al., 2001). Methyl glycolate is also known as methyl 2hydroxyacetate or glycolic acid methyl ester (38). Glycolic acid is the smallest alpha-hydroxy acid (AHA) which has both alcohol and acid groups. Because of its small molecular weight and size, it is able to efficiently penetrate skin and, thus, is extensively used in cosmetics. It is known that AHA diminishes the lines on the skin and make them look young by absorbing moisture in air and by exfoliating action to break the bonds between dead skin cells. Glycolic acid is naturally found in sugar beets, cane sugar and unripe grapes. Alkyl glycolates are important building blocks for the synthesis of medicines and agrochemicals. The glycolic acid content in honeys may be the reason that honey is widely incorporated into many different types of cosmetic products.

Palmitic acid (IUPAC name: hexadecanoic acid) and stearic acid (IUPAC name: octadecanoic acids) showed broad peaks in the chromatogram (Fig 4). Similar behavior was seen with the carboxyclic acids extracted from Palestinian honey using SPME (Odeh 
http://dx.doi.org/10.4314/ajtcam.v10i2.2

\begin{tabular}{|c|c|c|c|c|c|c|c|c|c|c|}
\hline & Compounds & $\begin{array}{c}\text { Petroleum } \\
\text { spirit }\end{array}$ & $\begin{array}{l}\text { R.T. } \\
\text { (min) }\end{array}$ & Hexane & $\begin{array}{l}\text { R.T. } \\
\text { (min) }\end{array}$ & Methanol & $\begin{array}{l}\text { R.T. } \\
\text { (min) }\end{array}$ & $\begin{array}{c}\text { Ethyl } \\
\text { acetate }\end{array}$ & $\begin{array}{l}\text { R.T } \\
\text { (min) }\end{array}$ & $\begin{array}{c}\text { Relative } \\
\text { Percentage }\end{array}$ \\
\hline 1. & Cis-linalool oxide & $\checkmark$ & 11.83 & & & & & & & 0.26 \\
\hline 2. & Linalool oxide & $\checkmark$ & 12.60 & & & & & & & 0.18 \\
\hline 3. & Dodecane & $\checkmark$ & 18.51 & $\checkmark$ & 18.49 & & & & & 0.05 \\
\hline 4. & n-tetratetracontane & $\checkmark$ & 70.60 & & & & & & & 0.06 \\
\hline 5. & Dioctyl phthalate* & $\checkmark$ & 71.74 & & & & & & & 0.04 \\
\hline 6. & Hexacosane & $\checkmark$ & 73.56 & $\checkmark$ & 73.61 & & & & & 3.66 \\
\hline 7. & Heptacosane & $\checkmark$ & 76.41 & $\checkmark$ & 76.53 & & & & & 6.34 \\
\hline 8. & Octacosane & $\checkmark$ & 79.17 & $\checkmark$ & 79.36 & & & & & 10.47 \\
\hline 9. & Nonacosane & $\checkmark$ & 81.84 & $\checkmark$ & 82.10 & & & & & 13.60 \\
\hline 10. & Triacontane & $\checkmark$ & 84.43 & $\checkmark$ & 84.68 & & & & & 12.50 \\
\hline 11. & Dotriacontane & $\checkmark$ & 86.94 & $\checkmark$ & 89.51 & & & & & 6.45 \\
\hline 12. & Eicosane & $\checkmark$ & 89.37 & & & & & & & 0.07 \\
\hline 13. & Heneicosane & & & $\checkmark$ & 57.60 & & & & & 0.04 \\
\hline 14. & Docosane & & & $\checkmark$ & 61.03 & & & & & 0.11 \\
\hline 15. & Tricosane & & & $\checkmark$ & 64.34 & & & & & 0.62 \\
\hline 16. & Tetracosane & & & $\checkmark$ & 67.54 & & & & & 1.35 \\
\hline 17. & Pentacosane & & & $\checkmark$ & 70.62 & & & & & 1.97 \\
\hline 18. & Tritetracontane & & & $\checkmark$ & 94.06 & & & & & 0.79 \\
\hline 19. & 1-dodecane & & & & & & & $\checkmark$ & 18.09 & 0.07 \\
\hline 20. & Cyclotetradecane & & & & & & & $\checkmark$ & 28.40 & 0.07 \\
\hline 21. & 1-hexadecane & & & & & & & $\checkmark$ & 37.80 & 0.10 \\
\hline 22. & 9-octadecane & & & & & & & $\checkmark$ & 46.20 & 0.12 \\
\hline 23. & Cycloeicosane & & & & & & & $\checkmark$ & 53.80 & 0.08 \\
\hline 24. & Acetic acid or Methyl glycolate & & & & & $\checkmark$ & 2.59 & & & 6.76 \\
\hline 25. & 2-furancarboxaldehyde & & & & & $\checkmark$ & 3.71 & & & 8.12 \\
\hline 26. & Furfural alcohol or 2-furanmethanol & & & & & $\checkmark$ & 4.66 & & & 4.06 \\
\hline 27. & 2-cyclopentene-1,4,-dione & & & & & $\checkmark$ & 4.90 & & & 2.25 \\
\hline 28. & Dihydro-butyrolactone or $2[3 \mathrm{H}]$-furanone & & & & & $\checkmark$ & 6.01 & & & 1.80 \\
\hline 29. & $\gamma$-crotonolactone or $2[5 \mathrm{H}]$-furanone & & & & & $\checkmark$ & 6.09 & & & 1.80 \\
\hline 30. & 2-hydroxy-2-cyclopenten-1-one & & & & & $\checkmark$ & 6.47 & & & 2.25 \\
\hline 31. & 2,4-dihydroxy-2,5-dimethyl-3[2H]-furan-3-one & & & & & $\checkmark$ & 8.16 & & & 3.16 \\
\hline 32. & Hyacinthin or phenylethanal & & & & & $\checkmark$ & 10.00 & & & 2.14 \\
\hline 33. & 2,3-dihydro-3, 5-hydroxy-6-methyl-4H-pyran-4one & & & & & $\checkmark$ & 17.53 & & & 2.82 \\
\hline 34. & HMF & & & & & $\checkmark$ & 22.21 & & & 4.40 \\
\hline 35. & Palmitic acid & & & & & $\checkmark$ & 52.80 & & & 0.85 \\
\hline 36. & Stearic acid & & & & & $\checkmark$ & 59.88 & & & 0.59 \\
\hline
\end{tabular}

* Contaminant; R.T. $=$ Retention Time 
Syazana et al., Afr J Tradit Complement Altern Med. (2013) 10(2):180-188 http://dx.doi.org/10.4314/ajtcam.v10i2.2

A)

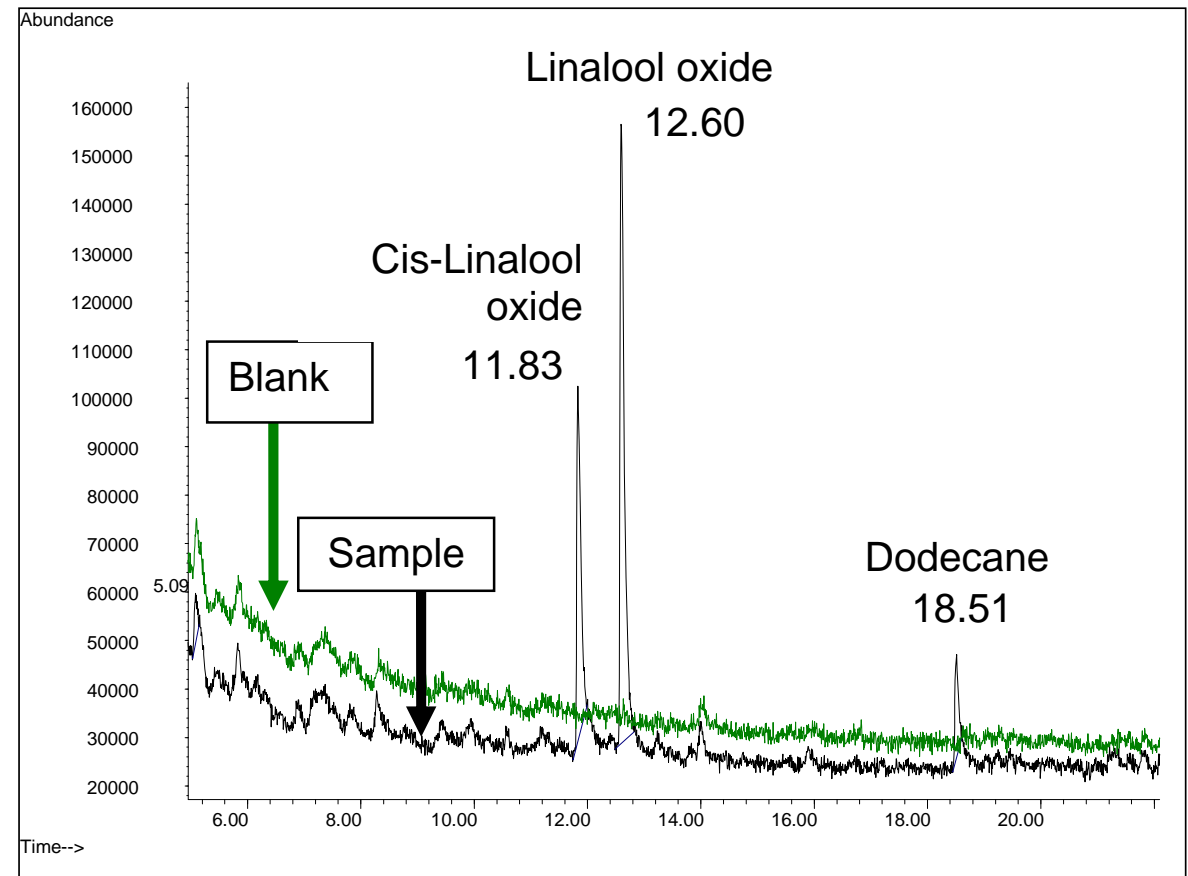

B)

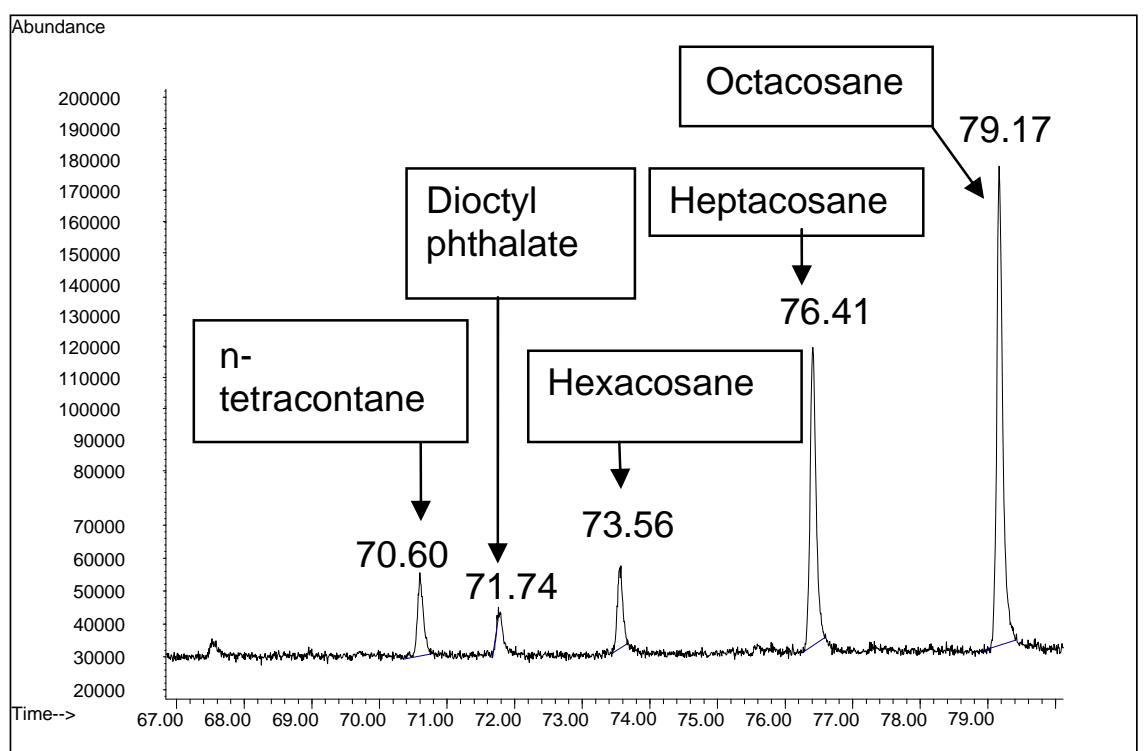

Figure 1: A) TIC of the petroleum spirit 40:60 extract of Tualang honey in the first 20 min and B) TIC of the petroleum spirit 40:60 extract of Tualang honey in the later run. 


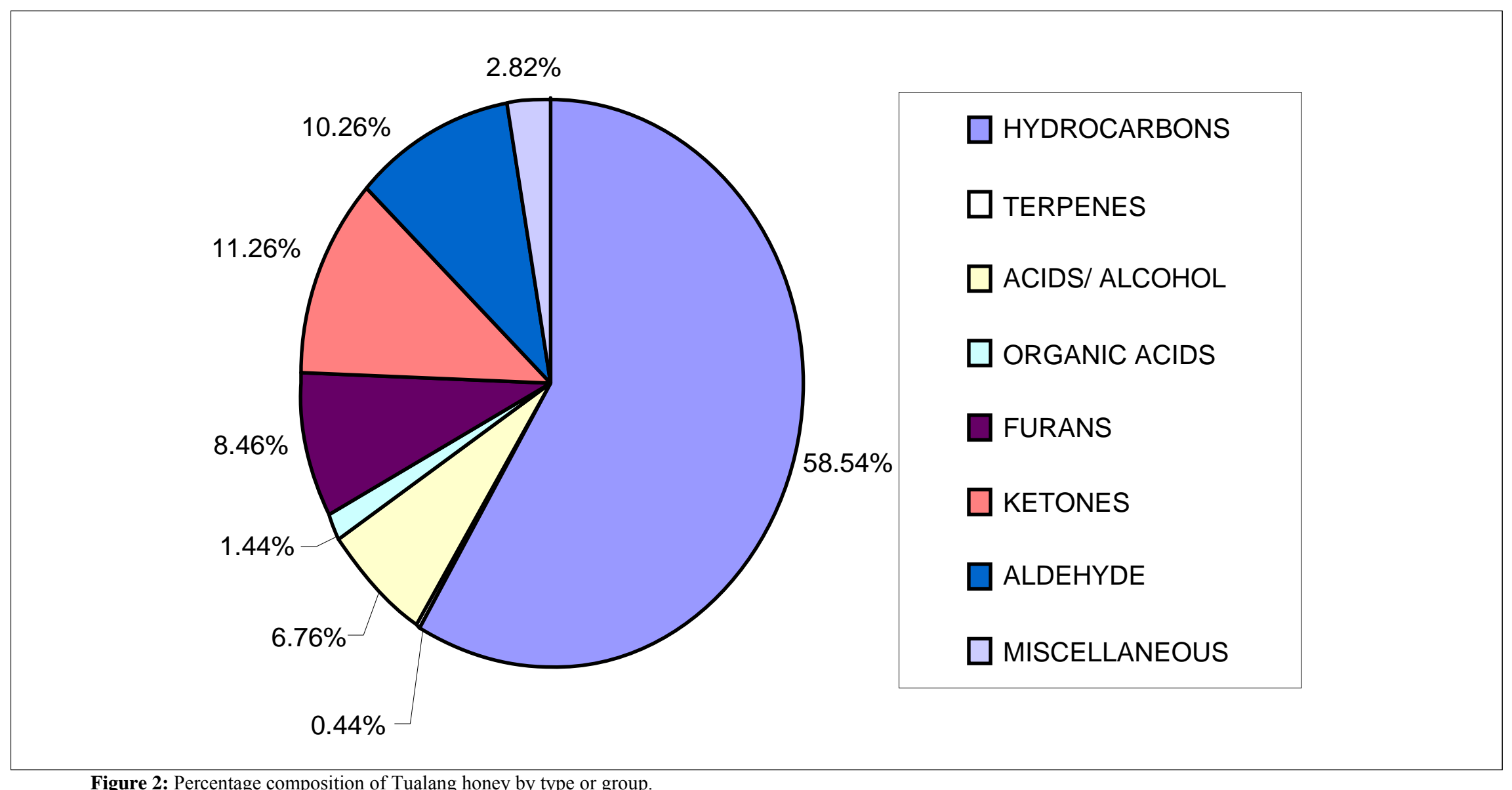

Figure 2: Percentage composition of Tualang honey by type or group. 


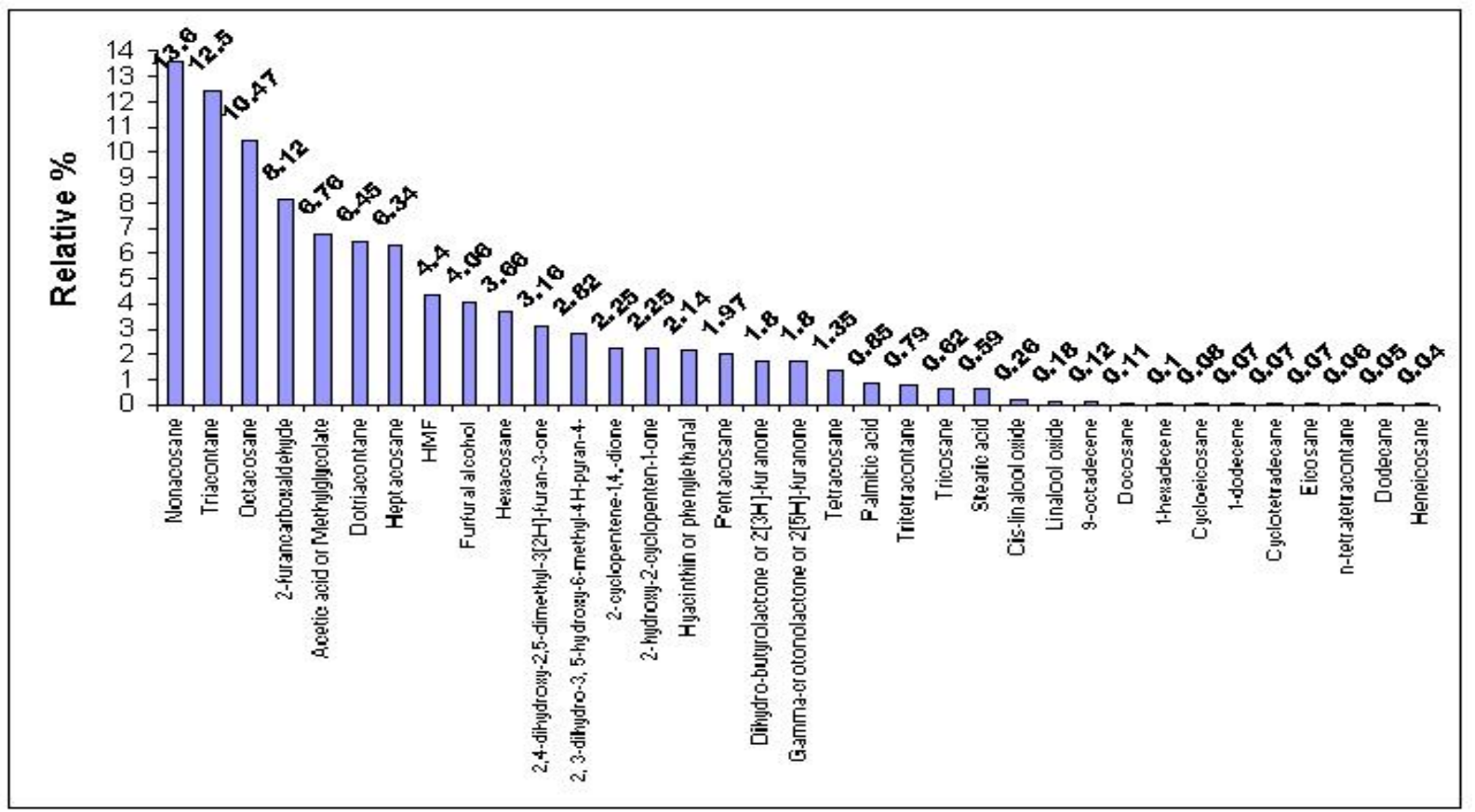

Figure 3: Volatile compounds detected in Tualang honey and their relative percentages.

et al., 2007). Palmitic acid has been identified in lavender honey extracted using ultrasonic solvent extraction (Jerkovic et al., 2001) and in lime tree honey samples (Lušić et al., 2007). Stearic acid has also been reported to be present in some honey types before. Both palmitic and stearic acids are saturated fatty acids, useful for biological function in the body. Aljadi \& Yusof (2003) in their study detected the presence of gallic acid in coconut and gelam honey but did not detect the presence of other phenolics in coconut honey. This indicates that Malaysian honey, specifically Tualang honey is unique and may be different from the rests of honey that originates from the same country.

Other organic acids which were not present in Tualang honey but which have been found in other honey samples include hexanoic (Jerkovic et al., 2001), decanoic acids (Castro Vasquez et al., 2006; Odeh et al., 2007), formic acid (Jerkovic et al., 2001), butanoic acid (Jerkovic et al., 2001), pentanoic acid (Jerkovic et al., 2001), heptanoic acid (Jerkovic et al., 2001), octanoic acids (Jerkovic et al., 2001), nonanoic acids (Jerkovic et al., 2001; Castro Vasquez et al., 2006), dodecanoic acids Jerkovic et al., 2001, abscisic acids (Yao et al., 2003), gallic acids (Aljadi et al., 2003; Yao et al., 2003), benzoic acid (Jerkovic et al., 2001; Aljadi et al., 2003), caffeic acid (Aljadi et al., 2003; Yao et al., 2003), cinnamic acid (Aljadi et al., 2003), ferrulic acids (Aljadi et al., 2003; Yao et al., 2003), coumaric acids (Yao et al., 2003) and syringic acids (Yao et al., 2003). The absence of some volatile compounds could also be considered as a useful tool for the characterization of honey. Radovic et al. (2001) reported that the absence of 3-methyl-1-butanol (isoamyl alcohol) could confirm the authenticity of lime tree floral types of honey.

A blank run was performed before the analysis of each volatile compound in order to confirm that there was no residual contamination of the column. We did, however, detect dioctyl phthalate contamination in our honey. This compound was likely to originate from the plasticizer in the plastic vial which contained the honey. However, its relative percentage was lower than any other volatile constituents detected in our analysis. Nevertheless, its presence indicates that honey is preferably stored in glass containers rather than in plastic containers when used for human consumption. Our study, however, has another limitation where the GC/MS peaks were identified by directly comparing the mass spectra of volatile compounds obtained with those reported in the NIST/Wiley libraries since no internal standards were included in the tested samples,

Other compounds identified include dihydro-butyrolactone or $2[3 \mathrm{H}]$-furanone, gamma-crotonolactone or $2[5 \mathrm{H}]-$ furanone, 2,4-dihydroxy-2,5-dimethyl-3[2H]-furan-3-one, hyacinthin or phenylethanal. Two compounds yielded from methanol extracts such as 2-cyclopentene-1,4,-dione and 2-hydroxy-2-cyclopenten-1-one, had not been previously reported. Since these compounds were not found in the volatile pattern of other types of honey samples, it is possible that they could be interesting chemical markers for the authentication of Tualang honey. 
http://dx.doi.org/10.4314/ajtcam.v10i2.2

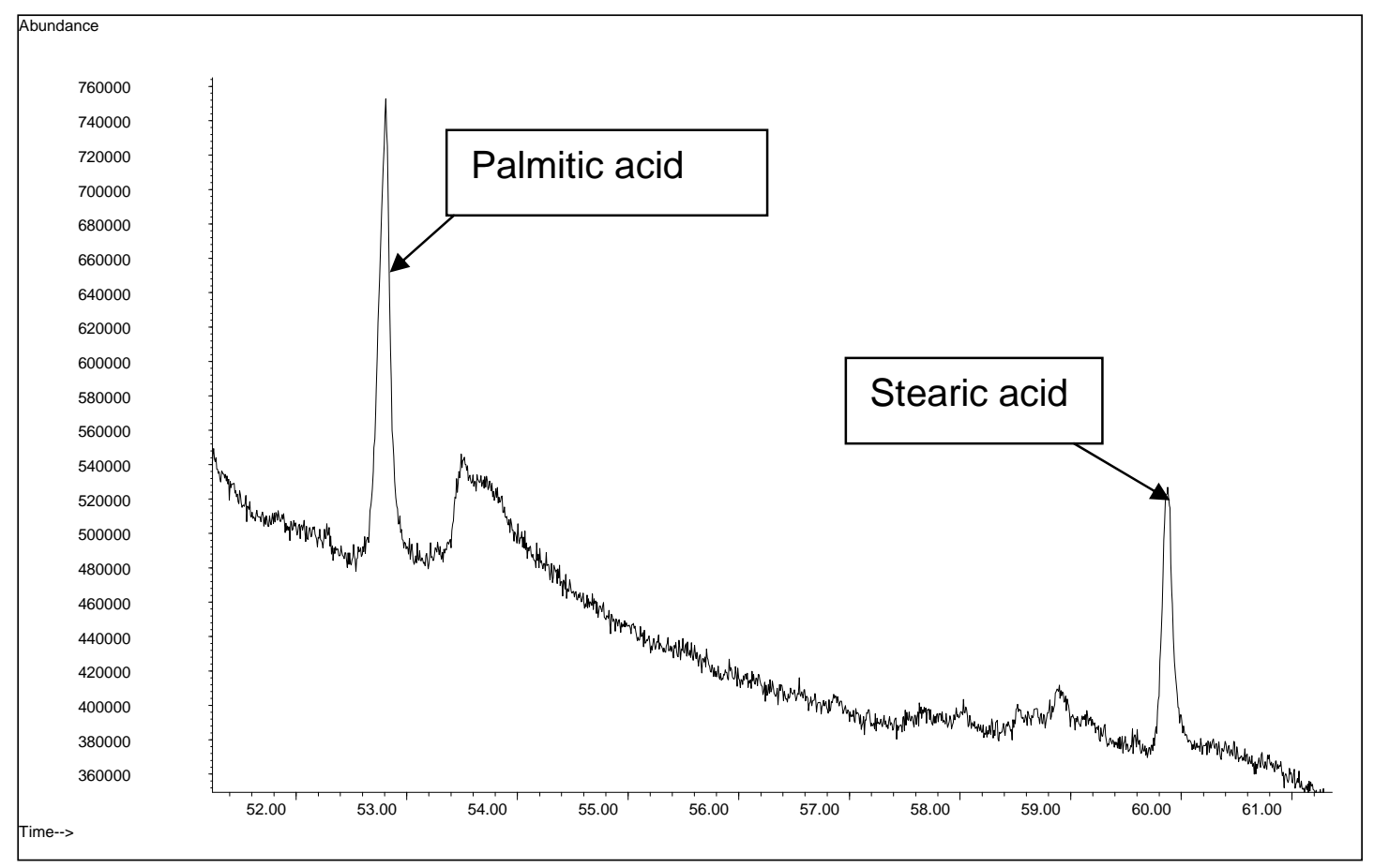

Figure 4: TIC of the methanol extract of Tualang honey in the later run.

\section{Conclusion}

Continuous liquid-liquid extraction followed by GC-MS is a useful method for isolation of volatile compounds in honeys, as the approach avoids heating of samples and allows fast and efficient quantification of volatile compounds usually found in honeys. Overall, 35 volatile constituents of Tualang honey was identified. Our results suggest that methanol is the best organic solvent to extract the active constituents of Tualang honey. Further research to test the clinical benefits of these volatile compounds and the effects of honey at cellular level should be performed.

\section{Acknowledgements}

The authors would like to acknowledge the Federal Agriculture Marketing Authority (FAMA) in Kedah, Malaysia for supplying the Tualang honey and all staff of the National Poison Centre (especially Puan Che Nin Man) for helping with this research. We would like to express our gratitude to Dr Norul Badriah Hassan for editing the manuscript. The authors would also like to thank the Malaysian Ministry of Higher Education for providing financial support under the FRGS grant (203/PPSP/6171105).

\section{References}

1. Alissandrakis, E., Daferera, D., Tarantilis, PA., Polissiou, MPC. (2009). Ultrasound-assisted extraction of volatile compounds from citrus flowers and citrus honey. Eur. Food Res. Technol., 229: 365-373.

2. Aljadi, AM., Yusoff, KM. (2003). Isolation and identification of phenolic acids in Malaysian honey with antibacterial properties. Turk J. Med. Sci., 33: 229-236.

3. Allisandrakis, E., Tarantilis, PA., Harizanis, PC., Polissiou, M. (2005). Evaluation of four isolation techniques for honey aroma compounds. J. Sc. Food Agric., 85: 91-97.

4. Al-Qassemi, R., Robinson, RK. (2003). Some special nutritional properties of honey: A brief review. Nutrition Food Sc. J., 3 (6): $254-$ 260.

5. Baroni, MV., Nores, ML., Díaz, MP., Chiabrando, GA., Fassano, JP., Costa, C., Wunderlin, DA. (2006). Determination of volatile organic compound patterns characteristic of five unifloral honey by solid-phase microextraction-gas chromatography-mass spectrometry coupled to chemometrics. J Agric. Food Chem., 54(19): 7235-7241.

6. Bentivenga, G., D'auria, M., Fedeli, P., Mauriello, G., Racioppi, R. (2004). SPME-GC-MS analysis of volatile organic compounds in honey from Basilicata. Evidence for the presence of pollutants from anthropogenic activities. Int. J. Food Sc. Tech., 39: 1079-1086. 
7. Bicchi, C., Belliardo, F., Frattini, C. (1983). Identification of the volatile components of some Piedmontese honeys. J. Apic. Res., 22: 130-136.

8. Bignell, CM., Dunlop, PJ., Brophy, JJ., Jackson, JF. (1994). Volatile Leaf Oils of Some South-western and Southern Australian Species of the Genus Eucalyptus. Part III - Subgenus Symphyomyrtus, Section Bisectaria, Series Macrocarpae. Flavour and Fragrance J., 9: 309-313.

9. Bouseta, A., Scheirman, V., Collin, S. (1996). Flavor and Free Amino Acid Composition of Lavender and Eucalyptus Honeys. J. Food Sci.,61: 683-687.

10. Castro Vasquez, L., Diaz-Maroto, MC., Guchu, EM., Perez-Coello, MS. (2006). Analysis of volatile compounds of eucalyptus honey by solid phase extraction followed by gas chromatography coupled to mass spectrometry. Eur. Food Res. Technol., 224: 27-31.

11. Castro Vasquez, L., Diaz-Maroto, MC., Perez-Coello, MS. (2007). Aroma composition and new chemical markers of Spanish citrus honeys. Food Chem., 103(2): 601-606.

12. Castro-V'Azquez, L., P'Erez-Coello, MS., Cabezudo, MD. (2003). Analysis of volatile compounds of rosemary honey. Comparison of different extraction techniques. Chromatographia., 57: 227-233.

13. Chemical Register. Chemical registry on methylglycolate. [Online] 2010 June; Available from: URL: http://www.chemicalregister.com/Methyl Glycolate\%20/Suppliers/pid22265.htm

14. Conrad R. High Fructose Corn Syrup and hydroxymethylfurfural. [Online] 2010 June; Available from: URL: http://www.beeculture.com

15. De La Fuente, E., Martinez-Castro, I., Sanz, J. (2005). Characterization of Spanish unifloral honeys by solid microextraction and gas chromatography-mass spectrometry. J. Sep. Sc., 28: 1093-1100.

16. De La Fuente, E., Sanz, ML., Martinez-Castro, I., Sanz, J., Ruiz-Matute, AI. (2007). Volatile and carbohydrate composition of rare unifloral honeys from Spain. Food Chem., 105(1): 84-93.

17. Jeffrey, AE., Carlos, ME. (1996) Medical Uses of Honey. Rev. Biomed., 7 (1): 43-49.

18. Jerković, I., Marijanović, Z., Kezić, J., Gugić, M. (2009). Headspace, volatile and semi-volatile organic compounds diversity and radical scavenging activity of ultrasonic solvent extracts from Amorpha fruticosa honey samples. Molecules Journal., 14: $2717-2728$.

19. Jerkovic, I., Marijanovic, Z. (2009). Screening of Volatile Composition of Lavandula hybrida Reverchon II Honey Using Headspace Solid-Phase Microextraction and Ultrasonic Solvent Extraction. Chemistry \& Biodiversity., 6: 421-430.

20. Kaškoniene, V., Venskutonis, PR., Ceksteryte, V. (2008). Composition of volatile compounds of honey of various floral origin and beebread collected in Lithuania. Food Chem., 111: 988-997.

21. Khalil, MI., Sulaiman, SA., Gan, SH. (2010). High 5-hydroxymethyl furfural concentrations are found in Malaysian honey samples stored for more than one year. J Food Toxic., 48: 2388-2392.

22. Luis, F., Cuevas-Glory, Pino, JA., Santiago, LS., Sauri-Duch, E. (2007). A review of volatile analytical methods for determining the botanical origin of honey. Sc. Direct J., 103: 1032-1043.

23. Lušić, D., Koprivnjak, O., Ćurić, D., Sabatini, A., Conte, LS. (2007). Volatile profile of Croatian lime tree (Tilia sp.), fir honeydew (Abies alba) and sage (Salvia officinalis) honey. Food Technol. Biotechnol., 45: 156-165.

24. Molan, PC. (2001). Potential of Honey in the Treatment of Wounds and Burns. Am. J. Clin. Dermatol., 2(1): 13-19.

25. Odeh, I., Abu-Lafi, S., Dewik, H., Al-Najjar, I., Imam, A., Valery, MO., Hanus, DL. (2007). A variety of volatile compounds as markers in Palestinian honey from Thymus capitatus, Thymelaea hirsuta, and Tolpis virgata. Food Chem., 101(4): 1393-1397.

26. Radovic, BS., Careri, M., Manglia, A., Musci, M., Gerboles, M., Anklam, E. (2001). Contribution of dynamic headspace GC-MS analysis of aroma compounds to authenticity testing of honey. Food Chem., 72(4): 511-520.

27. Saravana, K., Jaganathan, Mahitosh, M. (2009). Antiproliferative effects of honey and of its polyphenols: A review. J. Biomed. Biotech., 9: 1-13.

28. Schumacher, HH. (2004). Use of medical honey in patients with chronic venous leg ulcers after split-skin grafting. J. Wound Care., 10: 451-452.

29. Simon, A., Sofka, K., Wiszniewsky, G., Blaser, G., Bode, U. (2006). Wound care with antibacterial honey (Medihoney) in pediatric hematology-oncology. Support Care Cancer., 14: 91-97.

30. Soria, AC., Marti'Nez-Castro, I., Sanz, J. (2003). Analysis of volatile composition of honey by solid phase microextraction and gas chromatography-mass spectrometry. J. Sep. Sc., 26: 793-801.

31. Tan, HT., Rahman, AR., Gan, SH., Halim, AS., Hassan, SA., Sulaiman, SA., Singh, KKB. (2009). Antibacterial properties of Malaysian Tualang honey against wound and enteric microorganisms: Comparison with Manuka honey. BMC Complementary \& Alt. Med., 9: 34-42.

32. Tan, TS., Holland, PT., Wilkins, A., Molan, PC. (1988). Extractives from New Zealand honeys. White clover, manuka and kanuka unifloral honeys. J. Agric. Food Chem., 36: 453-460.

33. Tualang. [Online] 2010 May; Available from http://www.blueplanetbiomes.org/tualang.htm

34. Verzera, A., Campisi, S., Zappala, M., Bonaccorsi, I. (2001). Analysis of volatile compounds of eucalyptus honey by solid phase extraction followed by gas chromatography coupled to mass spectrometry. Am. Lab., 7: 18-21.

35. Wilkins, AL., Lu, Y., Tan, ST. (1993). Extractives from New Zealand honeys. Linalool derivatives and other components from nodding thistle (Carduus nutans) honey. J. Agric. Food. Chem., 41: 873-878.

36. Yao, L., Datta, N., Francisco, A., Tomas-Barbera, N., Ferreres, F., Martos, I., Singanusong, R. (2003). Flavonoids, phenolic acids and abscisic acid in Australian and New Zealand Leptospermum honeys. Food Chem., 8: 159-168.

37. Zappala, M., Fallico, B., Arena E., Verzera, A. (2005). Methods for determination of HMF in honey: a comparison. Food Control., 16: $273-277$. 